\title{
Outcomes of fertility preservation in women with endometriosis: comparison of progestin-primed ovarian stimulation versus antagonist protocols
}

Emmanuelle Mathieu d'Argent ${ }^{1,2}$, Clément Ferrier ${ }^{1,2^{*}}$ (D), Chrysoula Zacharopoulou ${ }^{3}$, Naouel Ahdad-Yata ${ }^{1,2}$, Anne-Sophie Boudy ${ }^{1,2}$, Adèle Cantalloube ${ }^{1}$, Rachel Levy ${ }^{4}$, Jean-Marie Antoine ${ }^{1,2}$, Emile Daraï ${ }^{1,2}$ and Sofiane Bendifallah ${ }^{1,2}$

\begin{abstract}
Background: PPOS protocols, initially described for FP in women with cancer, have many advantages compared to antagonist protocols. PPOS protocols were not evaluated for women with endometriosis. The objective of the study was to describe fertility preservation outcomes in women with endometriosis and to compare an antagonist protocol with a Progestin-Primed Ovarian Stimulation (PPOS) protocol.

Method: We conducted a prospective cohort study associated with a cost-effectiveness analysis in a tertiary-care university hospital. The measured outcomes included the numbers of retrieved and vitrified oocytes, and direct medical costs. In the whole population, unique and multiple linear regressions analysis were performed to search for a correlation between individual characteristics and the number of retrieved oocyte.
\end{abstract}

Results: We included 108 women with endometriosis who had a single stimulation cycle performed with either an antagonist or a PPOS protocol. Overall, $8.1 \pm 6.6$ oocytes were retrieved and $6.4 \pm 5.6$ oocytes vitrified per patient. In the multiple regression model, age $(p=0.001)$, prior ovarian surgery $(p=0.035)$, and anti-Mullerian hormone level $(p=0.001)$ were associated with the number of retrieved oocytes. Fifty-four women were stimulated with an antagonist protocol, and 54 with a PPOS protocol. A mean of $7.9 \pm 7.4$ oocytes were retrieved in the antagonist group and $8.2 \pm 5.6$ in the PPOS group ( $p=0.78$ ). A mean of $6.4 \pm 6.4$ oocytes were vitrified in the antagonist group and $6.4 \pm 4.7$ in the PPOS group $(p=1)$. In the cost-effectiveness analysis, the PPOS protocol was strongly dominant over the antagonist protocol.

Conclusion: Fertility preservation procedures are feasible and effective for patients affected by endometriosis. Antagonist and PPOS protocols were associated with similar results but the medico-economic analysis was in favor of PPOS protocols.

Keywords: Cryopreservation, Endometriosis, Assisted-reproductive technology, Cost-effectiveness, Infertility

\footnotetext{
* Correspondence: clement.ferrier@aphp.fr

'Department of Gynaecology and Obstetrics, Tenon University Hospital.

Assistance Publique des Hôpitaux de Paris (AP-HP). Faculty of Medicine Pierre

and Marie Curie. Sorbonne University, Paris, France

${ }^{2}$ Groupe de Recherche Clinique GRC6-UPMC : Centre Expert En

Endométriose (C3E), Paris, France

Full list of author information is available at the end of the article
}

(c) The Author(s). 2020 Open Access This article is distributed under the terms of the Creative Commons Attribution 4.0 International License (http://creativecommons.org/licenses/by/4.0/), which permits unrestricted use, distribution, and reproduction in any medium, provided you give appropriate credit to the original author(s) and the source, provide a link to the Creative Commons license, and indicate if changes were made. The Creative Commons Public Domain Dedication waiver (http://creativecommons.org/publicdomain/zero/1.0/) applies to the data made available in this article, unless otherwise stated. 


\section{Background}

Endometriosis represents a major public health challenge. Although its incidence is still difficult to assess accurately, it is thought to affect $10 \%$ of women of reproductive age worldwide and up to 40 to $50 \%$ of infertile women. In France, an estimated 2.1 to 4.2 million women are affected by endometriosis which is responsible for 30 to $40 \%$ of cases of hypo- or infertility [1-4].

In France, fertility preservation (FP) is authorized and has been fully covered by the healthcare system since the 2004 Bioethics Laws (modified in 2011) especially for women with potentially fertility-associated disorders such as endometriosis $[5,6]$. At the same time, with the worldwide trend of delaying childbearing in developed countries [7-9], the motivation for FP is growing.

Among the various techniques reported for FP (oocyte cryopreservation, freezing of embryos, and ovarian cortex cryopreservation) [10], oocyte cryopreservation has been reported to be the best option because of its low negative impact on ovarian reserve and low associated morbidity compared to other FP techniques [11].

In this setting, several ovarian stimulation protocols, originally developed for assisted reproduction technology (ART), have been used for FP especially for women with cancer. Recently, Kuang et al. described a progestinprimed ovarian stimulation (PPOS) protocol using exogenous progesterone to replace the GnRH agonist or antagonist in the follicular phase [12]. In their retrospective cohort study, compared with an antagonist short protocol the number of mature oocytes retrieved and the number of frozen embryos were not significantly different [13]. However, to the best of our knowledge, published data assessing the most effective stimulation protocol in the context of endometriosis are scarce.

Therefore, the aim of the current study was to analyze FP outcomes in women with endometriosis and to compare an antagonist protocol with a PPOS protocol in terms of FP outcome (retrieved and vitrified oocytes) and cost-effectiveness.

\section{Methods}

\section{Study setting and patients}

The data of all women diagnosed with endometriosis and referred for FP from July 2015 to October 2018 were extracted from the prospectively maintained database of Tenon University Hospital.

Inclusion criteria for FP were: i) age $<40$ years, ii) endometriosis with ovarian cysts with and without deep endometriosis (DE), and iii) alteration of ovarian reserve (antral follicle count (AFC) $<10$ and/or antiMullerian hormone $(\mathrm{AMH})$ level $<2)$. Indications for FP were systematically validated by a multidisciplinary committee.

\section{Procedures}

After having received relevant information and participated in a conference explaining the modalities of FP, each patient could choose whether to undergo a single cycle of the antagonist or PPOS protocol. Any patient on long-term oral progestin treatment who chose the antagonist protocol had to stop her progestin treatment and the protocol was started on the 1st or 2nd day of a natural cycle. For the PPOS protocol, patients could continue their long-term oral progestin treatment and start the protocol when they wished. Patients in the PPOS protocol without long-term oral progestin treatment started an oral treatment by desogestrel at the same time as ovarian stimulation, on the 1st day of a natural cycle. In both groups, gonadotropin (150/450 UI FSH or HMG) was injected daily according to body mass index (BMI), AMH and AFC. The dose of gonadotropins was monitored and adapted using transvaginal ultrasonography (assessing follicle number and size) and blood tests (luteinizing hormone (LH), estradiol (E2) and progesterone serum levels). In the antagonist protocol group, a GnRH antagonist (Ganirelix, orgalutran ${ }^{\bullet} \mathrm{MSD}$ France) was injected daily from day 6 to the trigger day. When three dominant follicles reached $18 \mathrm{~mm}$ in diameter, the final stage of oocyte maturation was triggered with the use of $0.2 \mathrm{mg}$ triptorelin (Decapeptyl; Ferring Pharmaceuticals) or Ovitrelle ${ }^{\oplus} 250 \mu$ g (Serono Europe limited lab). Transvaginal ultrasound-guided oocyte retrieval was performed $34-36 \mathrm{~h}$ after the trigger. All follicles with a diameter $>10 \mathrm{~mm}$ were retrieved. The aspirated oocytes were frozen by vitrification on the day of retrieval.

\section{Outcome measures}

The primary outcome measure was the number of oocytes retrieved during the cycle. Secondary measures included the number vitrified oocytes, the rate of moderate/severe ovarian hyperstimulation, the rate of cycle cancellation due to insufficient ovarian response and the rate of $\mathrm{LH}$ surge incidence ( $\mathrm{LH}$ level $>10 \mathrm{UI} / \mathrm{l})$.

\section{Cost-effectiveness analysis}

We considered all direct medical costs related to the FP procedure. The treatment doses, number of consultations, blood tests performed, and number of transvaginal ultrasonography exams were recorded for each patient applying the national regulated price (in 2018) for each element $[14,15]$. We assumed non-medical costs (transport, daily allowances ...) to be zero. As FP procedures are fully covered by the public health insurance in France and no extra services were charged, we also considered out-of-pocket expenditure to be zero. The temporal horizon was the duration of the cycle. Consequently, actualization processing was not necessary [16]. 


\section{Statistical analysis}

Patient characteristics, biological and sonographic parameters during the cycle and the number of oocytes retrieved and vitrified in each protocol were compared using Student test and $x^{2}$ tests. Statistical uni- and multivariate analysis were performed. For the medicoeconomic analysis, the protocols were compared on the basis of their effectiveness and costs. We performed all analysis using Stata/IC 14.0 and Excel 2013 software.

\section{Ethical approval}

Prospective recording of data was approved by the French Authority, the Advisory Committee on Information Processing in Healthcare Research (ID-RCB: 2018A01141-54).

\section{Results}

\section{Characteristics of the population}

A total of 196 women were referred for FP during the study period. Among them, 108 fulfilled the inclusion criteria and constituted the study population (Fig. 1: flow chart).

The mean age was 30.3 years, mean serum AMH level $2.0 \mathrm{ng} / \mathrm{ml}$, and mean AFC 11.3. Nearly all of the women (92\%) had DE including $42.7 \%$ with digestive involvement. Moreover, $70.4 \%$ of the women had a history of endometrioma. Before stimulation, 88 patients (82.2\%) were on oral progestin treatment. For the PPOS group, the progestin was promegestone $(n=23)$, chlormadinone $(n=22)$, medrogestone $(n=3)$, acetate of nomegestrol $(n=3)$, or desogestrel $(n=3)$. Patient characteristics were statistically comparable between the two groups (Table 1).

\section{Outcomes}

\section{Ovarian stimulation}

No significant differences were observed between the PPOS and antagonist protocols in terms of total dose of gonadotrophin $(p=0.281)$, duration of treatment $(p=$ $0.58)$, trigger method $(p=0.071)$, E2 and progestin levels on the trigger day ( $p=0.678$ and $p=0.44$, respectively). Stimulation parameters and hormone levels are reported in Table 2.

\section{Fertility preservation results (Table 2)}

Overall, the protocols resulted in $8.1 \pm 6.6$ retrieved oocytes and $6.4 \pm 5.6$ vitrified oocytes per patient. The mean \pm standard deviation of oocyte retrieved in the antagonist group and the PPOS group were 7.9 \pm 7.4 and $8.2 \pm 5.6$ oocytes, respectively $(p=0.78)$. The mean \pm standard deviation of oocytes retrieved in the antagonist group and the PPOS group were 6.4 \pm 6.4 and $6.4 \pm 4.7$ oocytes, respectively $(p=1)$.

\section{Multivariate regression model}

In the multiple regression model, age $(p=0.001)$, prior ovarian surgery $(p=0.035)$, and the AMH level $(p=$ 0.001 ) were associated with the number of retrieved oocytes. The presence of DE (versus superficial endometriosis alone), the location of endometriosis, the presence of endometrioma during the stimulation and the size of endometriomas were not associated with the number of retrieved oocytes $(p>0.05)$ (Table 3).

\section{Medico-economic analysis}

No differences were observed between the protocols in terms of duration of the stimulation, the total dose of gonadotropin, the number of consultations $(n=2)$,




Table 1 Characteristics of the study population

\begin{tabular}{|c|c|c|c|c|}
\hline & $\begin{array}{l}\text { Total } \\
(n=108)\end{array}$ & $\begin{array}{l}\text { Antagonist protocol } \\
(n=54)\end{array}$ & $\begin{array}{l}\text { PPOS protocol } \\
(n=54)\end{array}$ & $p$-value \\
\hline Age (years) (mean \pm SD) & $30.3 \pm 4.3$ & $30.8 \pm 4.6$ & $29.7 \pm 4.0$ & $0.19^{1}$ \\
\hline $\mathrm{BMI}\left(\mathrm{kg} / \mathrm{m}^{2}\right)($ mean $\pm \mathrm{SD})$ & $22.2 \pm 4.1$ & $21.9 \pm 2.6$ & $22.6 \pm 5.1$ & $0.35^{1}$ \\
\hline Smoking $(\%(n))$ & $31.5 \%(34 / 108)$ & $33 \%$ & $29 \%$ & $0.68^{2}$ \\
\hline Positive gravidity $(\%(n))$ & $20.5 \%(22 / 108)$ & $22 \%$ & $19 \%$ & $0.42^{2}$ \\
\hline Positive parity $(\%(n))$ & $6.5 \%(7 / 108)$ & $6 \%$ & $7 \%$ & $0.70^{2}$ \\
\hline Prior ovarian surgery $(\%(n))$ & $27.8 \%(30 / 108)$ & $31 \%$ & $24 \%$ & $0.39^{2}$ \\
\hline Prior surgery for endometrioma $(\%(n))$ & $21.5 \%(23 / 107)$ & $26 \%$ & $17 \%$ & $0.22^{2}$ \\
\hline Prior surgery for endometriosis $(\%(n))$ & $20.8 \%(22 / 106)$ & $17 \%$ & $25 \%$ & $0.34^{2}$ \\
\hline $\mathrm{AMH}(\mathrm{ng} / \mathrm{ml})($ mean $\pm \mathrm{SD})$ & $2.1 \pm 1,9$ & $2.1 \pm 2.4$ & $2 \pm 1.3$ & $0.82^{1}$ \\
\hline $\mathrm{AFC}(\mathrm{n})($ mean $\pm \mathrm{SD})$ & $11.3 \pm 6,8$ & $11.1 \pm 7.4$ & $11.5 \pm 6.2$ & $0.75^{1}$ \\
\hline Endometrioma during the FP $(\%(n))$ & $34.3 \%(36 / 105)$ & $31 \%$ & $38 \%$ & $0.45^{2}$ \\
\hline $\mathrm{DE}(\%(\mathrm{n}))$ & $92.1 \%(93 / 101)$ & $92 \%$ & $92 \%$ & $0.93^{2}$ \\
\hline DE with digestive involvement $(\%(n))$ & $42.7 \%(41 / 96)$ & $35 \%$ & $49 \%$ & $0.16^{2}$ \\
\hline Adenomyosis (\%(n)) & $25.5 \%(25 / 98)$ & $25 \%$ & $27 \%$ & $0.82^{2}$ \\
\hline Oral progestin treatment before $\mathrm{FP}(\%(\mathrm{n}))$ & $82.2 \%(88 / 107)$ & $76 \%$ & $89 \%$ & $0.08^{2}$ \\
\hline
\end{tabular}

BMI Body mass Index, AMH Anti-Mullerian Hormone, AFC Antral Follicular Count, DE Deep Endometriosis, SD standard deviation, FP Fertility Preservation; $P$-value for the comparison between the antagonist protocol and the PPOS protocol; 1: t-test; 2 : Chi2 test

the number of blood tests $(n=2)$ and the number of ultrasonography exams $(n=2)$ during the stimulation period. No complications occurred either during the stimulation or oocyte retrieval procedures. Consequently, the differences in costs between the two groups were for the $\mathrm{GnRH}$ antagonist for the antagonist group and the oral progestin treatment for the PPOS group.

For the antagonist group, the mean duration of GnRH antagonist treatment was 6.4 days (cost per day: $€ 34)$. A total of 341 days of treatment was required amounting to a total cost of $€ 11,600$ (i.e. $€ 215$ per patient).

For the PPOS group, the mean duration of progestin treatment was 13.2 days (cost per day: $€ 0.31$ ). A total of 713 days of treatment was required amounting to a total cost of $€ 319$ (i.e. $€ 6$ per patient).

Thus, the incremental cost of the antagonist protocol was $€ 11,281$ (i.e. $€ 209$ per patient). Both protocols were equivalent in terms of PF results. Consequently, the PPOS protocol was strongly dominant over the antagonist protocol.

Table 2 Stimulation parameter, hormone levels and number of mature follicles on the trigger day (or trigger day-1), retrieved and vitrified oocytes

\begin{tabular}{|c|c|c|c|c|}
\hline & $\begin{array}{l}\text { Whole population } \\
(n=108)\end{array}$ & $\begin{array}{l}\text { Antagonist protocol } \\
(n=54)\end{array}$ & $\begin{array}{l}\text { PPOS protocol } \\
(n=54)\end{array}$ & $p$-value \\
\hline Total dose of gonadotropins (UI) (mean \pm SD) & $3691 \pm 1247$ & $3826 \pm 1340$ & $3556 \pm 1247$ & $0.281^{1}$ \\
\hline Duration of the gonadotropin treatment (days) (mean $\pm S D$ ) & $11.3 \pm 2.1$ & $11.4 \pm 2.0$ & $11.2 \pm 2.1$ & $0.58^{1}$ \\
\hline Trigger: & & & & $0.071^{2}$ \\
\hline$-h c g$ & $12 \%$ & $19 \%$ & $6 \%$ & \\
\hline -decapeptyl GnRH analogue & $88 \%$ & $81 \%$ & $94 \%$ & \\
\hline Estradiol level (pg/ml) (mean \pm SD) & $1281 \pm 1392$ & $1342 \pm 1297$ & $1219 \pm 1494$ & $0.678^{1}$ \\
\hline LH level (UI/L) (mean \pm SD) & $0.40 \pm 0.63$ & $0.44 \pm 0.08$ & $0.24 \pm 0.06$ & $0.03^{1}$ \\
\hline Progestin level $(\mathrm{ng} / \mathrm{ml})($ mean $\pm \mathrm{SD})$ & $1.5 \pm 1.4$ & $1.4 \pm 1.2$ & $1.6 \pm 1.5$ & $0.44^{1}$ \\
\hline Number of mature follicles (mean \pm SD) & $8.5 \pm 5.2$ & $8.3 \pm 5.2$ & $8.6 \pm 5.2$ & $0.745^{1}$ \\
\hline Number of retrieved oocytes (mean \pm SD) & $8.1 \pm 6.6$ & $7.9 \pm 7.4$ & $8.2 \pm 5.6$ & $0.78^{1}$ \\
\hline Number of vitrified oocytes (mean \pm SD) & $6.4 \pm 5.6$ & $6.4 \pm 6.4$ & $6.4 \pm 4.7$ & $1^{1}$ \\
\hline
\end{tabular}

SD standart deviation; $P$-value for the comparison between the antagonist protocol and the PPOS protocol; 1: t-test; 2 : chi2 test 
Table 3 Simple and multiple linear regression on the number of retrieved oocytes

\begin{tabular}{llll}
\hline Variable & $\begin{array}{l}\text { Simple linear regression } \\
\text { Coefficient 95\%Cl }\end{array}$ & $p$-value & Multiple linear regression Coefficient 95\%Cl \\
\hline Age (years) & $-0.23[-0.35:-.011]$ & $<0.001$ & $-0.48[-0.76:-0.20]$ \\
BMI $\left(\mathrm{kg} / \mathrm{m}^{2}\right)$ & $0.35[-0.08: 0.15]$ & 0.56 & \\
Tobacco use & $-0.01[-0.02: 0.01]$ & 0.22 & \\
Prior pregnancy & $0.20[-2.3: 2.7]$ & 0.88 & \\
Prior surgery for DE & $0.52[-2.6: 3.7]$ & 0.74 & $-2.74[-5.28:-0.20]$ \\
Prior ovarian surgery & $-2.1[-4.9: 0.66]$ & 0.13 & \\
DE (vs. Superficial endometriosis only) & $0.1[-3.9: 4.1]$ & 0.96 & \\
Presence of endometrioma & $0.56[-2.1: 3.3]$ & 0.68 & \\
Presence of adenomyosis & $0.44[-2.5: 3.4]$ & 0.77 & $1.29[0.53: 2.05]$ \\
AMH (ng/ml) & $1.8[1.2: 2.4]$ & $<0.001$ & $0.13[-0.09: 0.34]$ \\
AFC (n) & $0.38[0.19: 0.57]$ & $<0.001$ & 0.035 \\
\hline
\end{tabular}

BMI Body Mass Index, DE Deep Endometriosis, AMH Anti-Müllerian Hormone, AFC Antral Follicular Count; Tested variables in the simple linear regression model included: body mass index, tobacco consumption, gravidity, parity, history of surgery for DE, presence of DE (vs. superficial endometriosis only), presence of adenomyosis, presence of endometrioma, size of the biggest endometrioma, cumulative size of the endometriomas, long-term oral progestin treatment, PPOS protocol (vs. antagonist protocol)

\section{Discussion}

To our knowledge, this is the largest observational cohort study analyzing FP results for women with endometriosis, and the first to compare PPOS and antagonist protocols in this setting. We demonstrate that both protocols result in a similar number of retrieved oocytes and vitrified mature oocytes. In addition, in the whole population, age, prior ovarian surgery, and the AMH level were strong prognostic factors of PF outcome. The incremental cost of the PPOS protocol was $€ 11,281$ ( $€ 209$ per patient) for the antagonist protocol making the PPOS protocol strongly dominant over the antagonist protocol.

The role of FP for patients with endometriosis is a major issue. The association between endometriosis and infertility is well recognized [4, 17], and several mechanisms have been implicated. The progressive loss of the follicle reservoir either spontaneously or after ovarian surgery is frequently observed $[18,19]$ and is often responsible for impaired fecundity, poor results in ART and an increased risk of premature ovarian failure. In this specific setting, we report the largest cohort $(n=$ 108) to assess FP outcome for women with endometriosis. In 2018, Raad et al. published a retrospective cohort study of 62 women with endometriosis [20]. Forty-nine patients completed at least one cycle with similar stimulation parameters as in our study (mean stimulation duration: $11.1( \pm 2.7)$ days; mean dose of gonadotropin used: $3634( \pm 1656)$ IU). In their series, the mean number of retrieved and vitrified oocytes were $9.5( \pm 6.1)$ and $7.2( \pm$ 4.9), respectively. In contrast to Raad et al.'s series, our patients were younger (30.3 vs. 33.9 years), more often affected by DE (92\% vs. $45 \%$ ) and had lower AMH levels ( 2.1 vs. $2.3 \mathrm{ng} / \mathrm{ml})$ and AFC (11.3 vs 13.0 follicles), potentially explaining the lower number of retrieved and vitrified oocytes in the current study. In the multivariate analysis, we also demonstrated that age, prior ovarian surgery and $\mathrm{AMH}$ levels were independent predictive factors of FP outcome. We thus suggest that FP should also be considered in patients at early stages of endometriosis when a reduced ovarian reserve is identified.

Several reports have studied the use of PPOS protocols for in vitro fertilization (IVF) procedures for women with endometriosis-associated infertility and found them to be more effective than other stimulation protocols [12, 21-26]. Indeed, a PPOS protocol has several advantages. It requires fewer injections than a conventional protocol, and may thus be considered more "userfriendly" for the patients. Moreover, patients with symptomatic endometriosis are usually under progestin treatment that can be continued for the initiation of a PPOS protocol. Finally, it should avoid the occurrence of painful menstruations before the ovarian stimulation, improving the tolerance of the procedure. PPOS protocols are thus easier to plan for both the physician and the patient. The PPOS protocol is also significantly cheaper, saving $€ 209$ per patient, and consequently strongly dominant over the antagonist protocol. We observed that the mean number of vitrified oocytes was 6.4 oocytes. Considering that the overall survival rate of vitrified oocytes has previously been evaluated at $85.2 \%$ (95\% CI $83.2-$ 87.2) [27], and that at least $8-10$ metaphase II oocytes are required to achieve a pregnancy [27], most patients will require at least two cycles of ovarian stimulation for an effective FP, reinforcing the efficiency of the PPOS protocol.

The issue of FP for women with endometriosis is attracting interest worldwide. In 2018, the National French College of Obstetrics and Gynaecology (CNGOF) 
included FP in the guidelines for endometriosis management. These guidelines state that FP should be proposed to: (1) patients with endometrioma, especially in the case of bilateral endometriomas or a history of ovarian surgery and, (2) patients with isolated DE [28]. However, these recommendations are based on limited existing literature data and the indications deserve to be clarified by continuous data collection together with growing experience with FP in the context of endometriosis, taking both the economic burden and success rates into consideration.

In our cohort, a large part $(41 \%)$ of the patients referred for a FP consultation and retained by the multidisciplinary committee had not undergone an FP procedure at the time of the study. This is somewhat surprising given that FP procedures are fully covered by the public health insurance in France. Nevertheless, we do not know how many of these patients (1) refused to undergo an FP procedure or (2) had planned a procedure which had not been performed at the time of the study. The causes for potential refusal should be explored in future studies to better select patients (and hence to decrease the cost of exams required for planning an FP procedure), and to improve patient information about the objectives and interests of FP in endometriosis.

Our study has several limitations. First, it was not a randomized-controlled trial and the choice of a protocol was based on patients' preferences. The number of patients in each group was the same because of chance. Even though the two groups were comparable on observable parameters, we cannot exclude that unobservable parameters may differ and bias the results. Second, during the initial evaluation most of the patients were on hormonal treatment (80\% were taking oral progestin). The effect of hormonal treatment on AMH level remains a matter of debate [29], but few studies suggest that progestin drugs tend to decrease AMH levels [30]. Third, we chose the number of retrieved and vitrified oocytes as outcome measures. No data about the oocyte quality or pregnancy outcomes after fertilization were available due to the short follow-up. Four, we assumed direct non-medical and productivity costs to be zero in our medico-economic analysis. Indeed, these data were unavailable in the database and no estimation could be extracted from the literature. However, in our experience, no physician prescribes medical transportation or sick leave for FP.

\section{Conclusion}

Our results highlight that FP procedures are feasible and effective for patients with endometriosis, even if several cycles will be required for most patients. Antagonist and PPOS protocols are associated with similar outcome in terms of number of retrieved and vitrified oocytes with a medico-economic analysis in favor of PPOS protocols. We suggest that data should be collected on a continuous basis to further clarify indications for FP in the context of endometriosis, taking both the economic burden and success rates into consideration.

\section{Acknowledgements \\ Authors would like to acknowledge the medical and paramedical team of the department of Gynecology-Obstetrics of Tenon University Hospital.}

\section{Authors' contributions}

EM A, C F, C Z, N A-Y, A-S B, A C, R L, J-M A, ED and SB substantially contributed to conception and design, or acquisition of data, or analysis and interpretation of data, drafted the article or revised it critically for important intellectual content, and finally approved the version to be published.

\section{Funding}

None.

Availability of data and materials

The datasets used and/or analysed during the current study are available from the corresponding author on reasonable request.

\section{Ethics approval and consent to participate}

Prospective recording of data was approved by the French Authority, the Advisory Committee on Information Processing in Healthcare Research (IDRCB: 2018-A01141-54)

Consent for publication

Not applicable.

\section{Competing interests}

The authors declare that they have no competing interests.

\section{Author details}

${ }^{1}$ Department of Gynaecology and Obstetrics, Tenon University Hospital. Assistance Publique des Hôpitaux de Paris (AP-HP). Faculty of Medicine Pierre and Marie Curie. Sorbonne University, Paris, France. ${ }^{2}$ Groupe de Recherche Clinique GRC6-UPMC : Centre Expert En Endométriose (C3E), Paris, France. ${ }^{3}$ Department of Gynaecology and Obstetrics. Military hospital Bégin, Saint-Mandé, France. ${ }^{4}$ Department of Histology, Embryology, cytogenetic, CECOS. Hôpital Jean Verdier. Assistance Publique des Hôpitaux de Paris (AP-HP), Bondy, France.

Received: 22 October 2019 Accepted: 5 February 2020

Published online: 13 February 2020

\section{References}

1. Giudice LC, Kao LC. Endometriosis. Lancet Lond Engl. 2004;364(9447):178999.

2. Eskenazi B, Warner ML. Epidemiology of endometriosis. Obstet Gynecol Clin North Am juin. 1997:24(2):235-58.

3. Dunselman GA, Vermeulen N, Becker C, Calhaz-Jorge C, D'Hooghe T, De Bie $B$, et al. ESHRE guideline: management of women with endometriosis. Hum Reprod Oxf Engl. 2014;29(3):400-12.

4. Meuleman C, Vandenabeele B, Fieuws S, Spiessens C, Timmerman D, D'Hooghe T. High prevalence of endometriosis in infertile women with normal ovulation and normospermic partners. Fertil Steril juill. 2009;92(1): $68-74$.

5. Loi n $2004-800$ du 6 août 2004 relative à la bioéthique. Available at: https://www.legifrance.gouv.fr/affichTexte.do?cidTexte= JORFTEXTO00000441469. Accessed 15 Apr 2019.

6. LOI n² 2011-814 du 7 juillet 2011 relative à la bioéthique. Available at: https://www.legifrance.gouv.fr/affichTexte.do?cidTexte= JORFTEXTO00024323102. Accessed 15 Apr 2019.

7. Centers for Disease Control and Prevention (CDC), 2011. Reproductive health. Infertility FAQs. Available at: <http://www.cdc.gov/ reproductivehealth/Infertility/index.htm> (Accessed 15 Apr 2019). 
8. SOGC. Society of obstetrician and gynaecologists of Canada: opinion committee, delayed childbearing. J Obstet Gynaecol Can. 2012;34: 80-93.

9. Volant. Un premier enfant à 28,5 ans en $2015: 4,5$ ans plus tard qu'en 1974. Available at: https://www.insee.fr/fr/statistiques/2668280. Accessed 15 Apr 2019.

10. Donnez J, Dolmans M-M. Fertility Preservation in Women. N Engl J Med. 2017;377(17):1657-65.

11. Cobo A, Diaz C. Clinical application of oocyte vitrification: a systematic review and meta-analysis of randomized controlled trials. Fertil Steril. 2011 96(2):277-85.

12. Kuang $Y$, Chen $Q, F u ~ Y$, Wang $Y$, Hong $Q$, Lyu Q, et al. Medroxyprogesterone acetate is an effective oral alternative for preventing premature luteinizing hormone surges in women undergoing controlled ovarian hyperstimulation for in vitro fertilization. Fertil Steril. 2015;104(1):62-70.e3.

13. Wang $N$, Wang $Y$, Chen Q, Dong J, Tian H, Fu Y, et al. Luteal-phase ovarian stimulation vs conventional ovarian stimulation in patients with normal ovarian reserve treated for IVF: a large retrospective cohort study. Clin Endocrinol (Oxf). 2016;84(5):720-8.

14. Base de donnée publique des médicaments. Available at: https://solidaritessante.gouv.fr/soins-et-maladies/medicaments. Accessed 15 Nov 2018.

15. CCAM. Classification Commune des Actes Médicaux. Available at: https:// www.ameli.fr/accueil-de-la-ccam/index.php. Accessed 15 Nov 2018.

16. Department of economics and public health assessment. Choices in methods for economic evaluation. 2012. https://www.has-sante.fr/portail/ jcms/r_1499251/fr/choix-methodologiques-pour-I-evaluation-economique-ala-has. Accessed 13 Mar 2019.

17. Prescott J, Farland LV, Tobias DK, Gaskins AJ, Spiegelman D, Chavarro JE, et al. A prospective cohort study of endometriosis and subsequent risk of infertility. Hum Reprod Oxf Engl. 2016;31(7):1475-82.

18. Seyhan A, Ata B, Uncu G. The impact of endometriosis and its treatment on ovarian reserve. Semin Reprod Med. 2015;33(6):422-8.

19. Goodman LR, Goldberg JM, Flyckt RL, Gupta M, Harwalker J, Falcone $T$. Effect of surgery on ovarian reserve in women with endometriomas, endometriosis and controls. Am J Obstet Gynecol. 2016;215(5):589.e1-6.

20. Raad J, Sonigo C, Tran C, Sifer C, Durnerin IC, Grynberg M. Oocyte vitrification for preserving fertility in patients with endometriosis: first observational cohort study ... and many unresolved questions. Letter to the Editor. Eur J Obstet Gynecol Reprod Biol. 2018;220:140-1.

21. Wang Y, Chen Q, Wang N, Chen H, Lyu Q, Kuang Y. Controlled Ovarian Stimulation Using Medroxyprogesterone Acetate and hMG in Patients With Polycystic Ovary Syndrome Treated for IVF: A Double-Blind Randomized Crossover Clinical Trial. Medicine (Baltimore). 2016;95(9): e2939.

22. Zhu $X$, Zhang $X, F u$ Y. Utrogestan as an effective oral alternative for preventing premature luteinizing hormone surges in women undergoing controlled ovarian hyperstimulation for in vitro fertilization. Medicine (Baltimore). 2015:94(21):e909.

23. Zhu X, Ye H, Fu Y. Comparison of neonatal outcomes following progesterone use during ovarian stimulation with frozen-thawed embryo transfer. Sci Rep. 2017;7(1):7835.

24. Iwami N, Kawamata M, Ozawa N, Yamamoto T, Watanabe E, Moriwaka O, et al. New trial of progestin-primed ovarian stimulation using dydrogesterone versus a typical $\mathrm{GnRH}$ antagonist regimen in assisted reproductive technology. Arch Gynecol Obstet. 2018;298(3):663-71.

25. Huang $C-Y$, Chen G-Y, Shieh M-L, Li H-Y. An extremely patient-friendly and efficient stimulation protocol for assisted reproductive technology in normal and high responders. Reprod Biol Endocrinol RBE. 2018;16(1):18.

26. Yu S, Long H, Chang HY-N, Liu Y, Gao H, Zhu J, et al. New application of dydrogesterone as a part of a progestin-primed ovarian stimulation protocol for IVF: a randomized controlled trial including 516 first IVF/ICSI cycles. Hum Reprod Oxf Engl. 2018;33(2):229-37.

27. Cobo A, García-Velasco JA, Coello A, Domingo J, Pellicer A, Remohí J. Oocyte vitrification as an efficient option for elective fertility preservation. Fertil Steril. 2016;105(3):755-764.e8.

28. Decanter C, d'Argent EM, Boujenah J, Poncelet C, Chauffour C, Collinet P, et al. Endometriosis and fertility preservation: CNGOF-HAS Endometriosis Guidelines. Gynecol Obstet Fertil Senol. 2018;46(3):368-72.

29. D'Arpe S, Di Feliciantonio M, Candelieri M, Franceschetti S, Piccioni MG, Bastianelli C. Ovarian function during hormonal contraception assessed by endocrine and sonographic markers: a systematic review. Reprod Biomed Online. 2016;33(4):436-48.

30. Birch Petersen K, Hvidman HW, Forman JL, Pinborg A, Larsen EC, Macklon $\mathrm{KT}$, et al. Ovarian reserve assessment in users of oral contraception seeking fertility advice on their reproductive lifespan. Hum Reprod Oxf Engl. 2015; 30(10):2364-75

\section{Publisher's Note}

Springer Nature remains neutral with regard to jurisdictional claims in published maps and institutional affiliations.
Ready to submit your research? Choose BMC and benefit from:

- fast, convenient online submission

- thorough peer review by experienced researchers in your field

- rapid publication on acceptance

- support for research data, including large and complex data types

- gold Open Access which fosters wider collaboration and increased citations

- maximum visibility for your research: over $100 \mathrm{M}$ website views per year

At BMC, research is always in progress.

Learn more biomedcentral.com/submissions 